\title{
A PÓS-GRADUAÇÃO STRICTO SENSU NO BRASIL: UM ESTUDO A PARTIR DOS DOCUMENTOS LEGAIS
}

\author{
THE POST-GRADUATION SCORTS SENSU IN BRAZIL: \\ A STUDY FROM LEGAL DOCUMENTS \\ LA POST-GRADUACIÓN STRICTO SENSU EN BRASIL: \\ UN ESTUDIO A PARTIR DE LOS DOCUMENTOS LEGALES
}

\begin{abstract}
Nathália Delgado Bueno Da Silva ${ }^{1}$
Carlos Da Fonseca Brandẽ ${ }^{2}$

${ }^{1}$ Universidade Estadual Paulista "Júlio de Mesquita Filho"(UNESP), Marília/SP - Brasil. ${ }^{2}$ Universidade Estadual Paulista "Júlio de Mesquita Filho"(UNESP), Marília/SP - Brasil.
\end{abstract}

Resumo O presente estudo tem por objetivo identificar os direcionamentos destinados à pós-graduação, stricto sensu, no Brasil no decorrer dos anos. Esse nível de ensino emerge no país de maneira regulamentada na década de 1960, garantindo-se atualmente como um sistema de ensino, possuindo representatividade e status acadêmico frente à pós-graduação lato sensu. $\mathrm{O}$ estudo é de caráter bibliográfico e documental, tomando por base o Parecer n. 977 de 3 de dezembro de 1965 e os Planos Nacionais de Pós-Graduação (PNPG), que de forma diretiva interferiram para que esse nível de ensino se consolidasse. Os documentos refletem as pretensões e necessidades da época em que englobam, estando articulados ao contexto social, político e econômico. Essa reflexão pode ser constatada pela linearidade na pós-graduação em determinados ciclos, como sua iniciação legal e a necessidade de estabelecer diretrizes formais para unificar os programas, posteriormente, as intenções em aferir a qualidade da expansão e, assim, a manutenção de um sistema que, nos dias atuais, é tema de diversas discussões, seja sobre a sua avaliação, seja acerca da sua organização e conjuntura. Palavras-chave: Pós-Graduação stricto sensu; Plano Nacional de Pós-Graduação (PNPG); Políticas Públicas Educacionais.

Abstract The present study aims to identify the directions for post-graduation, stricto sensu, in Brazil over the years. This level of education emerged in the country in a regulated manner in the $1960 \mathrm{~s}$, and is now guaranteed as a teaching system, with representation and academic status in front of the post-graduate lato sensu. The study is of a bibliographic and documentary nature, based on Opinion n. 977 of December 3, 1965 and the National 
Graduate Plans (PNPG), which in a directive way interfered so that this level of education was consolidated. The documents reflect the pretensions and needs of the era in which they encompass, being articulated to the social, political and economic context. This reflection can be verified because there is linearity in the postgraduate in certain cycles, as its legal initiation and the need to establish formal guidelines to unify the programs; later, the intentions to measure the quality of the expansion, and thus, the maintenance of a System, that today is the subject of several discussions, whether about its evaluation, or about its organization and conjuncture.

Keywords: Postgraduate Stricto Sensu; National Graduate Plan (PNPG); EducaTiOnAl Public Policies.

RESUMEN El presente estudio tiene por objetivo identificar los directivos destinados al postgrado, stricto sensu, en Brasil a lo largo de los años. Este nivel de enseñanza emerge en el país de manera regulada en la década de 1960, garantizándose actualmente como un sistema de enseñanza, que posee representatividad y estatus académico frente al posgrado lato sensu. El estudio es de carácter bibliográfico y documental, tomando como base el Dictamen n. 977 de 3 de diciembre de 1965 y los Planes Nacionales de postgrado (PNPG), que de manera directiva interfirieron para que este nivel de enseñanza se consolidara. Los documentos reflejan las pretensiones y necesidades de la época en que engloban, estando articulados al contexto social, político y económico. Esta reflexión puede ser constatada pues hay linealidad en el postgrado en determinados ciclos, como su iniciación legal y la necesidad de establecer directrices formales para unificar los programas; a continuación, las intenciones en medir la calidad de la expansión, y así, el mantenimiento de un sistema, que hoy es tema de diversas discusiones, sea sobre su evaluación, sea sobre su organización y coyuntura.

Palabras clave: Postgrado stricto sensu; Plan Nacional de Postgrado (PNPG); Políticas Públicas Educativas.

\section{INTRODUÇÃo}

A pós-graduação stricto-sensu foi regulamentada no país na década de 1960, especificamente em 1969, por meio do Parecer n. 77 de 11 de fevereiro. No entanto, o documento que se torna referência neste contexto é o Parecer n. 977, de 3 de dezembro de 1965, intitulado "Definição dos Cursos de Pós-Graduação", visto que apresentou diferentes elementos à pós-graduação que estão sendo até hoje utilizados, evidenciando tanto aspectos em nível macro, tratando-se do sistema de ensino, quanto em nível micro, relacionados aos programas e cursos de pós-graduação.

Na década seguinte, surge o Plano Nacional de Pós-Graduação (PNPG), documento que serviu de base para a implantação das regulamentações e diretrizes posteriores. Os planos são documentos relevantes que evidenciam dados relacionados à situação da pós-graduação em diferentes momentos históricos, bem como, as pretensões e projeções almejadas, pontuando as diretrizes pertinentes para tal. Está em vigência o quinto Plano Oficial 
da Pós-Graduação (V PNPG 2011-2020), sendo que os anteriores datam dos períodos: I PNPG (1975-1979); II PNPG (1982-1985); III PNPG (1986-1989); IV PNPG (2005-2010).

Visando identificar os direcionamentos destinados à Pós-graduação stricto sensu no Brasil, o presente estudo toma por base os documentos supracitados, salientando os principais aspectos abordados e que interferiram de maneira direta na organização e constituição dos programas de pós-graduação no cenário nacional.

Considera-se relevante a temática pela necessidade de observação e análise do histórico para o entendimento integral das diretrizes atuais. Por meio dos principais documentos legais que delinearam a pós-graduação desde a sua gênese, é possível compreender, justificar e até mesmo fundamentar as opções e direcionamentos atuais. Parte-se do pressuposto de que as políticas educacionais não são deslocadas, mas se apresentam como consequência de articulações legais e histórico-sociais.

\section{GÊNESE LEGAL E O PARECER ATEMPORAL}

Os estudos acerca da pós-graduação stricto sensu no Brasil revelam que o Parecer n. 977, de 3 de dezembro de 1965, constitui-se como marco legal e impulsionador desse nível de ensino no país. Por esse motivo e considerando os elementos que este se propõe a evidenciar, é que se toma a liberdade de nomeá-lo enquanto parecer atemporal, ou seja, um clássico e proporcionador de diretrizes e delimitações que até hoje vigoram.

O referido parecer, intitulado "Definição dos cursos de pós-graduação", apresenta oito itens que permitem o entendimento do nível de ensino em tal época, seja sobre como estava acontecendo, seja acerca de suas pretensões. Ele expressa uma iniciativa do ministro da Educação requerendo ao Conselho definições mais exatas aos cursos no Brasil, apontando as imprecisões existentes. Segundo o próprio documento, é necessário regulamentar a pós-graduação no país, não apenas defini-la.

A pós-graduação sob a forma de cursos de mestrado e doutorado é fenômeno recente no ensino superior brasileiro. Mas seu aparecimento no cenário de nossa educação superior não é o fruto de uma decisão intempestiva do Conselho Federal de Educação. É o resultado de um processo intimamente vinculado ao movimento de modernização da universidade brasileira, que teve seu início na década de 50 (SUCUPIRA, 1980, p. 3).

A pós-graduação, imersa em sua parte teórica e prática, garante ênfase tanto na pesquisa, quanto na formação de profissionais para o mercado de trabalho, no entanto, salienta-se que as atividades profissionais são de cunho científico, daí a relevância da diferenciação entre pós-graduação stricto e lato sensu. ${ }^{1}$ Aliás, é em tal documento que as nomeclaturas aparecem com suas devidas definições, servindo de pressuposto para as organizações curriculares até os dias presentes.

1 A pós-graduação sensu stricto apresenta as seguintes características fundamentais: é de natureza acadêmica e de pesquisa e mesmo atuando em setores profissionais tem objetivo essencialmente científico, enquanto a especialização, via de regra, tem sentido eminentemente prático-profissional; confere grau acadêmico e a especialização concede certificado; finalmente, a pós-graduação possui uma sistemática formando estrato essencial e superior na hierarquia dos cursos que constituem o complexo universitário (BRASIL, 1965, p. 4). 
Esse parecer, visto sempre como a base doutrinária e normativa da pós-graduação sistemática, será referência constante das outras normatizações que se lhe seguiram e para a solução de questões suscitadas na implantação dos programas e dos cursos (CURY, 2005, p. 14).

Declaradas as suas intenções em possibilitar que o país tenha um sistema de pós-graduação organizado, o seu histórico em nível mundial é evidenciado pela sua origem reportada à estrutura da Universidade Norte-americana. Esse dado é relevante, pois tal contexto surge novamente quando o parecer indica um exemplo de pós-graduação: a norte-americana. A gênese identificada é justamente a base a ser seguida, considerando que o item destinado a exemplificar não é aleatório, nem mesmo a título de curiosidade, mas expressa um modelo sugerido.

A partir dos elementos mencionados no parágrafo anterior, é importante refletir a influência do contexto no parecer, ou seja, estando o país imerso no momento em que a Ditadura Militar estava à frente, o incentivo à Educação, em um primeiro momento, pode parecer controverso, porém, havia o entendimento acerca da necessidade de formar mão de obra qualificada para impulsionar o desenvolvimento do país. Assim, reforçando a fala de Hostins (2006, p. 136) entende-se que "[...] a presença americana no movimento de consolidação da pós-graduação e de reforma da educação superior brasileira, em grande medida, explica o interesse e apoio do regime militar".

Acerca do contexto, a autora supracitada fornece dados relevantes que justificam o interesse do regime militar relacionado às universidades. Hostins (2006) demonstra que houve alianças entre academia e militares na definição de políticas à instituições de ensino superior, bem como, reforça o pano de fundo, que de certa forma é substancial para o entendimento de tal interesse, ancorado na ideia de que ciência e tecnologia são indispensáveis para o progresso do país, assim, justifica-se a alternativa pela formação universitária.

Não há como trazer o contexto do regime militar e desvinculá-lo das inúmeras atrocidades inerentes a ele. Inclusive, nesse mesmo contexto, outros países da América Latina tiveram suas universidades públicas desmanteladas, por exemplo, Chile, Argentina e Uruguai. A diferença foi que no Brasil o ideal nacionalista de construção de um país potência "[...] conduziu o governo à articulação com dirigentes e representantes da comunidade científica e universitária com vistas à modernização da universidade e da ciência e tecnologia, resultando na definição de políticas" (HOSTINS, 2006, p. 138).

Reafirma-se a relevância da compreensão do contexto de forma articulada à reflexão dos documentos, pois a intenção do avanço das universidades e da pós-graduação, por exemplo, não foi um fato isolado frente a um contexto de censura no país. É inegável o impulso que a pós-graduação teve nesse período, porém, é necessário um olhar e reflexão ampliados, justamente para compreender que havia intenções para além de benefícios à própria universidade e pós-graduação. Além da "[...] burocratização das universidades que, transformadas em pesadas organizações exigiam a consequente regulação e controle das atividades desenvolvidas, principalmente nos programas de pós-graduação" (HOSTINS, 2006, p. 138).

Retomando o documento, é interessante observar que a todo momento a referência de fora do país é mais evidente do que a busca a partir de elementos próprios, mencionados pelo próprio documento devido à limitada experiência que tínhamos a esse respeito. Se- 
gundo Cury (2005, p. 15-16), “[...] a nossa fragilidade científica era vista mais como causa do "atraso" do que como consequência de uma dependência mais ampla e de uma exclusão secular em matéria de educação nacional, especialmente na escolarização básica".

É sabido que no país havia cursos de pós-graduação, no entanto, o referido parecer se torna o documento que marca o início da regulamentação, pois anteriormente não existia uma definição clara de seus objetivos, estrutura, entre outros.

A competência adquirida no exterior somava-se aquela já conseguida dentro do
próprio país, e tinha-se, então, como resultado, a ampliação do número de pes-
quisadores e professores dentro Brasil. Esse corpo docente constituir-se-ia na
"massa crítica" que daria suporte humano à criação do sistema. Pode-se dizer
que a consolidação do sistema de pós-graduação no Brasil, desde o final dos
anos de 1960, contou também com o investimento consciente, propiciado pelo
Estado, em matéria de capacidade adquirida no exterior (CURY, 2005, p. 7).

Retomando o modelo sugerido, foram definidos os níveis de mestrado e doutorado, considerados autônomos, ainda que representassem um escalonamento. Ou seja, um não seria pré-requisito para o outro, ficando suas aberturas flexíveis às universidades, frente os diferentes campos de saber e suas especificidades. Assim, "[...] o mestrado pode ser encarado como etapa preliminar na obtenção do grau de doutor ou como grau terminal" (BRASIL, 1965, p. 10). É importante destacar que se aconselhava a dedicação do estudante em tempo integral, pelo menos nos períodos mínimos exigidos para ambos os níveis.

Foi previsto duração mínima, em termos de ano letivo, de um ano para o mestrado e dois para o doutorado. Nesse período, o estudante teria um leque de disciplinas disponíveis e o total de estudos exigidos seria contabilizado por meio de créditos. ${ }^{2}$ Era considerando a necessidade de estudos individuais, além de margem de tempo para atividades afins, propondo-se horas de trabalhos escolares por ano letivo, ou seja, aulas, seminários, laboratórios, entre outros, contabilizando o total de 360 horas para o mestrado e 450 para o doutorado. Os estudos exigidos se voltavam ao cumprimento de matérias relativas à sua área de concentração e ao domínio conexo. ${ }^{3} \mathrm{O}$ estudante também deveria submeter-se a exames gerais para a verificação da sua capacidade de leitura em línguas estrangeiras, sendo pelo menos uma para o mestrado e duas para o doutorado. Ao término, as exigências definidas para o mestrado e doutorado eram diferentes, onde no mestrado era exigida a dissertação, como elemento a demonstrar o domínio do tema escolhido e capacidade de sistematização do estudante, e no doutorado, a defesa da tese que apresentasse contribuição para o conhecimento na área escolhida (BRASIL, 1965).

As definições aos programas também são mencionadas, como a necessidade de propiciar uma amplitude de disciplinas, de modo que o estudante teria opções, bem como, o de-

2 Sistema que, aliás, já vem sendo adotado no curso de mestrado mantido pelo Instituto de Química da Universidade do Brasil. Nesse curso, se requer um mínimo de 30 créditos, correspondendo o crédito a cada 17 horas de aulas teóricas ou equivalentes. Por não existir ainda unidade de crédito convencionada para nosso ensino superior deixamos de empregar esse critério de avaliação (BRASIL, 1965, p. 9).

3 Por área de concentração entende-se o campo específico de conhecimento que constituirá o objeto de estudos escolhido pelo candidato, e por domínio conexo qualquer matéria não pertencente àquele campo, mas considerada conveniente ou necessária para completar sua formação (BRASIL, 1965, p. 10). 
ver de constituir coordenação específica ao nível de pós, além da necessidade da autonomia do estudante frente às suas possibilidades durante o mestrado e doutorado, sendo auxiliado por um diretor de estudos, que se remete hoje ao orientador. Tratando-se dos estudantes de doutorado, estes podem receber atividades docentes, sem haver prejuízo em sua formação.

Também havia flexibilidade no que dizia respeito ao ingresso de estudantes com diferentes formações iniciais, desde que tivesse determinada afinidade entre as áreas. Ainda sobre o ingresso, ficou definido por lei o diploma de graduação como requisito de matrícula, porém, os cursos de pós “[...] poderão estabelecer requisitos que assegurem rigorosa seleção intelectual dos candidatos. Se os cursos de graduação devem ser abertos ao maior número, por sua natureza, a pós-graduação há de ser restrita aos mais aptos" (BRASIL, 1965, p. 11).

Os moldes indicados apresentam características similares aos atuais, como o sistema de créditos, por exemplo, e a necessidade de prova em língua estrangeira. A organização do tempo do estudante também é bastante parecida, sendo mencionada a necessidade de dois momentos, um destinado às aulas e a um seminário que verifique o andamento e capacidade do estudante e outro destinado à escrita do trabalho, dissertação ou tese e aprofundamento das leituras.

Outra especificação diz respeito à necessidade de determinação específica dos tipos de mestrado e doutorado, seja como acadêmicos ou profissionais. Há uma série de dificuldades em estabelecer nomenclaturas devido às especificidades das diferentes áreas, assim, é proposto que o mestrado "[...] seja qualificado pela denominação do curso, área ou matéria correspondente” (BRASIL, 1965, p. 10). Acerca do doutorado, propõe-se:

\footnotetext{
Como é possível lograr-se uma classificação sistemática livre de qualquer objeção sugerimos que o doutorado seja articulado com as quatro grandes áreas seguintes: Letras, Ciências Naturais, Ciências Humanas e Filosofia. Quanto aos doutorados profissionais, teriam a designação do curso correspondente como, por exemplo, Doutor em Engenharia, Doutor em Medicina, etc (BRASIL, 1965, p. 10).
}

A aprovação dos cursos de pós-graduação fica a cargo do Conselho Federal de Educação (CFE) e o registro dos diplomas ao Ministério da Educação. Nota-se que o parecer apresenta elementos definitivos em termos de organização da pós-graduação em seus níveis macro e micro. Ao considerá-la como categoria própria, distinta da especialização e do aperfeiçoamento, ensejando assim uma interpretação que tornou possível o conceito oficial de pós-graduação atualmente em vigor (SUCUPIRA, 1980, p. 14). Pensando o nível macro enquanto nacional, prevê uma série de definições, indo desde a nomenclatura até a natureza da pós-graduação, que serve como pano de fundo a qualquer curso existente. Em nível micro é observado definições de questões mais técnicas dos cursos, como o tempo de duração, que é algo com a flexibilidade prevista, bem como, a organização de disciplinas e até mesmo a possibilidade de abertura de programas apenas de mestrado ou doutorado.

\section{Plano Nacional de Pós-Graduação (PNPG)}

O Plano Nacional da Pós-graduação (PNPG) constitui-se como uma política ampla a esse nível de ensino. Ampla por evidenciar e refletir diferentes questões, como um panora- 
ma da pós-graduação em determinado contexto histórico e social, bem como, em diversas regiões brasileiras, ou até mesmo, direcionando elementos para a avaliação dos cursos, refletindo projeções e desafios, o que de forma inerente constitui seu caráter político. $\mathrm{O}$ referido documento tem como objetivo definir diretrizes, estratégias e metas para dar continuidade e avançar nas propostas para a política de pós-graduação e pesquisa no Brasil. ${ }^{4}$ Dessa forma, constitui-se enquanto a referência para a promoção e implementação de políticas públicas a esse nível de ensino.

Até o momento há cinco Planos Nacionais direcionados à pós-graduação, divididos por períodos, são eles: I PNPG (1975-1979); II PNPG (1982-1985); III PNPG (1986-1989); IV PNPG (2005-2010); V PNPG (2011-2020). Os referidos documentos trazem as preocupações e metas de seu contexto, porém, articulados, visto que, os anos que englobam se esgotam, porém, a pós-graduação continua e, assim, a política que a direciona deve manter uma linearidade coerente.

O I Plano 5 (1975-1979), dez anos após a institucionalização da pós-graduação no país, período recente à preocupação em sistematizar e organizar esse nível de ensino, que até então, ocorrera no Brasil de forma desalinhada. Segundo o referido Plano, com ele se pretende evoluir para uma nova etapa do sistema universitário, durante a qual as atividades de pós-graduação assumirão importância estratégica crescente (BRASIL, 1975, p. 119).

Havia os pareceres que regulamentavam aspectos a esse nível de ensino, no entanto, a fragilidade da pós-graduação é evidente quando comparado à solidez em nível de Sistema Nacional visto atualmente. Assim, considerando a recente instituição legal da pós no país, as poucas normativas que se destinavam para tal e o crescimento de cursos isolados, a criação do I Plano Nacional é compreendida na presente pesquisa como um dos fundamentais aspectos iniciais para a consolidação do Sistema que temos hoje. O documento unifica diretrizes, ampliando os pareces existentes até então, estabelece um panorama do que é encontrado, bem como, faz projeções em nível de Brasil, ou seja, é uma política mais abrangente.

Analisando o sumário do documento, especificamente no item "Objetivos e Diretrizes Gerais" é possível observar suas intenções e devidas articulações ao contexto. O item ramifica-se em: 1) Institucionalização do sistema de pós-graduação; 2) Elevação dos padrões de desempenho e; 3) Planejamento da expansão.

Nota-se que, para além das referências às necessidades daquele período, no que diz respeito a uma organização mais precisa da pós-graduação, também apresenta ideias que vão além, podendo ser caracterizadas como pretensões atuais como, por exemplo, ao mencionar a integração entre os níveis de ensino, que culminou na criação da Diretoria de Educação Básica na CAPES, ${ }^{6}$ elemento presente no PNPG vigente (2011-2020).

Consegue-se visualizar também a intenção e o objetivo da pós-graduação que perpassa a presente política, quando menciona que os cursos desse nível de ensino "devem ser dirigidos para a formação de recursos humanos para o próprio ensino superior”, ou seja, formação acadêmica, docente universitária, sem se distanciar da atividade de pesquisa, que

\footnotetext{
4 Disponível em: http://www.capes.gov.br/plano-nacional-de-pos-graduacao. Acesso em: 20 abr. 2019.

5 Elaborado pelo Conselho Nacional de Pós-Graduação, instituído no Ministério da Educação e Cultura pelo Governo Federal, por meio do Decreto n. 73.411, de 4 de janeiro de 1974.

6 Coordenação de Aperfeiçoamento de Pessoal de Nível Superior (CAPES).
} 
entra como foco quando articulada ao ensino, independentemente do nível. O interessante nesse momento, é observar a preocupação do plano em preparar o estudante para a escrita de sua tese ou dissertação.

[...] que os alunos sejam, desde a sua admissão, preparados em atividades de pesquisa, investigação e produção de textos, como treinamento para o trabalho de tese, ao invés de simplesmente adiá-lo para após a obtenção dos créditos (BRASIL, 1975, p. 136).

Parece óbvio tal elemento, considerando a pós-graduação e que a produção e escrita de uma pesquisa é inerente ao processo, porém, observando a prática dos programas e o modelo atual de avaliação, nota-se que a escrita da pesquisa em si não é um elemento evidenciado, por esse motivo chama a atenção a preocupação para esse item, algo extremamente necessário, pois a qualidade de uma tese ou dissertação não está somente em seu conteúdo, mas também na escrita e na forma de organização científica. Parte-se do pressuposto de que na inserção do estudante na pós-graduação este saberá escrever, visto o nível de ensino, porém, considerando a extensividade e complexidade que constitui uma pesquisa científica e acadêmica em nível de mestrado e doutorado, são rasas as experiências que perpassam os níveis anteriores.

Naquele momento, os dados indicavam que havia 50 instituições que realizam a pós-graduação, sendo elas: "25 federais, 10 estaduais e municipais e 15 particulares (BRASIL, 1975). A título de curiosidade, os dados de 2009 evidenciam 2.719 programas em atividade e responsáveis por 4.101 cursos. De 1976 a 2009, houve um crescimento de 370,3\% no número de cursos de mestrado e 685,6\% nos doutorados" (BRASIL, 2010, p. 46). A expressividade dos dados não para aí. No contexto do I PNPG os números mostram cerca de 13.500 estudantes e 7.500 docentes nesse nível, no ano de 1973 (BRASIL, 1975). Nos dados de 2009, constam 161.117 estudantes matriculados e 57.270 docentes (BRASIL, 2010).

É importante reforçar a preocupação do I PNPG com a qualidade dos cursos, principalmente quando diz respeito à elevação dos padrões de desempenho. Porém, enfatiza-se que, no atual contexto é primordial em um primeiro momento a expansão e organização dos referidos programas, visto que a sua inserção foi "solta" pelo país, com padrões diversos e relacionados às próprias instituições de ensino. Tal elemento é reforçado quando se observa que "[...] o padrão qualitativo da pós-graduação brasileira, legitimada e consolidada pelo regime militar, se expandiu e deu espaço à intelectualidade crítica e atuante no horizonte cultural do país" (HOSTINS, 2006, p. 138).

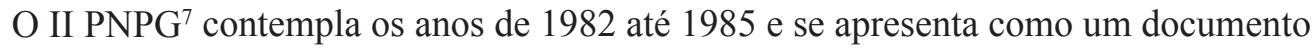
mais reduzido que o I Plano. Seus anexos, que se constituem como a seção do documento em si, possuem 11 folhas e se dividem em cinco itens: 1 - Premissas Básicas da Política Nacional de Pós-Graduação; 2 - Situação da Pós-Graduação; 3 - O papel da Pós-Graduação no contexto nacional; 4 - Os objetivos básicos do Plano Nacional de Pós-Graduação; 5 - Prioridades e diretrizes.

7 Aprovado pelo Decreto n'. 87.814, de 16/11/82 e publicado no D.O.U. de 18/11/82, Seção I, p. $21469-21471$. 
O objetivo central do plano é a formação de recursos humanos qualificados para atividades docentes, de pesquisa em todas as suas modalidades e técnicas, para atendimento às demandas dos setores público e privado (BRASIL, 1982, p. 177). É interessante ressaltar, neste momento, que o documento, de forma inerente ao anúncio de seu objetivo central, ressalta a relevância de uma formação de recursos humanos para além da conservação e reprodução do conhecimento incorporado, mas sim, na capacidade de avanço com contribuições significativas.

A justificativa para tal é a de que reproduzir o conhecimento representa apenas a capacidade de incorporá-lo, enquanto o avançar, significa a representação real de domínio de determinada especialidade (BRASIL, 1982). Ou seja, apropriar-se para reproduzir é mais simples e se constitui como capacidade limitada, logo que, induz o mesmo do mesmo, enquanto apropriar para avançar significa contribuir com elementos a mais, o que de fato representa uma apropriação mais significativa, pois combate a repetição, conservação e reprodução do que está posto.

É possível compreender a situação da pós-graduação no referido momento, a partir das menções do plano em item específico. Segundo ele:

\begin{abstract}
Apesar de todos os esforços, ainda persistem alguns dos problemas estruturais que dificultam a institucionalização e consolidação da pós-graduação. A excessiva dependência de recursos extraorçamentários, a sujeição a repentinos cortes de verbas, a instabilidade empregatícia e profissional dos docentes, técnicos e pessoal de apoio, continuam sendo problemas básicos da pós-graduação atual (BRASIL, 1982, p. 178).
\end{abstract}

Não há mecanismos institucionais suficientes para uma plena realização da pós-graduação, ainda que seja um avanço a existência das pró-reitorias e de órgãos colegiados (BRASIL, 1982). A partir do cenário atual é ainda mais interessante refletir tal afirmação, pois se vive em um contexto em que a pós-graduação se mantém como um sistema sólido, apesar de críticas a serem consideradas e debatidas acerca do aferimento de sua qualidade e outros elementos.

A questão da qualidade aparece como deficitária nesse contexto, em que num processo de expansão quantitativa do sistema, em muitos casos, levou a um distanciamento dos padrões de qualidade considerados ideais (BRASIL, 1982, p. 180). Tal assertiva merece destaque, visto que no Plano anterior foi possível observar que a expansão tinha mais ênfase do que a qualidade e, agora, no contexto do II PNPG, a questão da qualidade passa na frente.

A elaboração do I PNPG foi responsabilidade do Ministério da Educação e Cultura junto ao Conselho Nacional de Pós-Graduação e o II PNPG, e os próximos ficaram sob responsabilidade da CAPES, ${ }^{8}$ que ganhou reconhecimento formal, em 1981, como orgão responsável pela elaboração do documento, após a extinção do Conselho Nacional de Pós-graduação.

O III PNPG, data de 1986 a 1989, e apresenta algumas características interessantes que o diferem dos anteriores. Desde o primeiro houve a intenção de legitimar as diretrizes do documento a partir do contexto prático, ou seja, do que estava acontecendo na pós-gra-

8 Nesse contexto, também é reconhecida pelo MEC como a agência executiva do Sistema Nacional de Ciência e Tecnologia. 
duação e considerando as suas relações, no entanto, o III Plano reforça desde o seu início as propostas dos anteriores, as conquistas e as intenções para os anos a seguir, e este recebe um tom mais autoritário.

Menciona-se logo em seu início que o país não possui a capacidade quantitativa de formação de cientistas que seja adequada para atingir a curto prazo uma plena capacitação tecnológica e científica. Dessa forma é proposto que seja:

[...] essencial iniciar, com a maior brevidade possível, um programa agressivo de formação de recursos humanos qualificados, tendo em vista que a sociedade e o governo pretendem a independência econômica, científica e tecnológica para o Brasil no próximo século (BRASIL, 1986, p. 193).

Dessa forma, reafirmam-se as políticas de governo e a intenção na formação quantitativa e qualitativa de pessoal capacitado para atuação e desenvolvimento do país.

Frente os anos anteriores, o documento aponta duas conquistas à pós-graduação, relacionando-as aos planos estabelecidos, sendo elas: 1) Aumento de profissionais com regime de tempo integral e dedicação exclusiva; 2) Consolidação do Sistema de avaliação e acompanhamento dos programas. Tais itens são destacados, porém, outros são apontados, por exemplo, a formação de uma melhora na qualidade dos programas de pós-graduação que, segundo o documento, mais da metade apresentam desempenho bom e excelente.

Mesmo com aspectos substancialmente positivos, o documento reafirma a heterogeneidade de programas e como consequência o crescimento nem sempre linear entre eles, apontando que $40 \%$, por exemplo, ainda apresentam deficiências, interferindo na qualidade de formação a esse nível. Pontos como evasão de alunos, problemas na seleção e elevado tempo para titulação também foram mencionados. Tais aspectos encontram-se em nível micro, considerando que refletem elementos presentes nos programas em si, porém, pontos mais amplos também são mencionados, como a questão dos financiamentos e sua instabilidade que acarreta cortes e atrasos de verbas devido à percepções imediatistas das políticas governamentais, reverberando nas frequentes mudanças de prioridades. Além de que:

Cabe ressaltar, portanto, que os financiamentos exclusivamente de curto prazo têm contribuído sobremaneira para a instabilidade dos grupos de pesquisa, os quais, freqüentemente, interrompem, temporária ou definitivamente, seus trabalhos de investigação científica; as administrações das instituições e os pesquisadores têm sido obrigados a dispender enorme esforço e tempo na elaboração continuada de projetos destinados à captação de recursos para manutenção de atividades de pesquisa. Assim sendo, o esforço desenvolvido nas atividades-meio tem desviado recursos humanos e materiais que seriam de outro modo apropriadamente utilizados nas atividades-fim (BRASIL, 1986, p. 200).

Nos planos anteriores o item financiamento aparece em diferentes momentos, ficando evidente a necessidade para aberturas de novos programas e manutenção, porém, no contexto do III PNPG fica mais evidente a articulação entre financiamento e avaliação dos programas.

Assim, tendo tais pressupostos para efetivação orçamentária, o mecanismo para utilização dos parâmetros relaciona-se com a avaliação destinada aos programas, que segundo 
o documento "[...] facilita a cobrança de resultados e o aperfeiçoamento do sistema" (BRASIL, 1986, p. 201). Na prática, programas que atingem conceitos avaliativos suficientes conseguem o financiamento que, por conseguinte, auxiliará para uma progressão e/ou conservação do referido conceito ou nota avaliativa.

Interessante refletir uma destinação orçamentária ancorada em critérios objetivos, no entanto, por sua vez, esse processo reforça a dificuldade de alguns programas para atingir o conceito desejado, bem como, para a sua manutenção, levando à questão: os critérios avaliativos incorporados como auge a ser alcançado, necessariamente refletem os elementos de um curso de qualidade, pensando nas diferentes regiões? Vale ressaltar que o ponto refletido a partir de tal política de financiamento aparece no documento quando expõe que o mesmo é efetivado a cada seis meses, permitindo que haja nos programas periódicas revisões que, segundo suas falas, propicia a oportunidade de inserção dos cursos em outros padrões. De qualquer forma, mesmo havendo a avaliação em curto prazo, a reflexão supracitada continua em voga, justamente porque o fator tempo pode ser considerado acessório frente aos demais elementos que asseguram conceitos de referência para um programa.

Acerca das regiões, é relevante demonstrar a disparidade presente na distribuição dos programas no país, em dados de 1982.

Releva acentuar que é ainda muito pequena a participação da região amazônica no processo de capacitação de pessoal em nível de pós-graduação stricto-sensu, que em 1982 apresentava a seguinte distribuição geográfica: Região Norte O,85\% Região Nordeste 11,03\% Região Centro-Oeste 3,13 \% Região Sudeste $74,21 \%$ Região Sul 10,75\% (BRASIL, 1986, p. 203).

É acentuada a necessidade de incentivo e prioridade de condições à abertura de programas em nível stricto sensu na região amazônica, porém, os dados refletem elementos não diferentes dos encontrados atualmente, conforme será visto ao discutir o plano vigente. Em linhas gerais, os objetivos apresentados ao III PNPG são:

1. consolidação e melhoria do desempenho dos cursos de pós-graduação; 2. institucionalização da pesquisa nas universidades, para assegurar o funcionamento da pós-graduação; 3 integração da pós-graduação no sistema de Ciência e Tecnologia, inclusive com o setor produtivo (BRASIL, 1986, p. 195).

Nota-se que os objetivos complementam e aprimoram os expressos nos planos anteriores, justamente quando deparamos com palavras como consolidar, ou seja, algo já foi iniciado e agora está caminhando, ou até mesmo quando menciona a institucionalização da pesquisa, demonstrando que pode ser notado que entra como atividade base da pós-graduação. Aliás, esse ponto fica evidente quando é mencionado acerca da institucionalização como precedente para assegurar o funcionamento. $\mathrm{O}$ item três reforça a pós-graduação para além de um nível de ensino isolado, ou seja, prevendo formação de pessoal para inserção em âmbito social mais amplo, assim como foi destaque no II Plano.

Para além dos objetivos, o III PNPG levanta questão em item específico acerca da influência da pós-graduação, elemento não mencionado até então pelos demais planos. Há o apontamento de que atividades de ensino e pesquisa provenientes desse nível de ensino 
não são adequadamente aproveitadas devido à falta de integração entre graduação e pós-graduação e refletindo em um nível mais amplo, “[...] a inexistência de uma política de incentivos que estimule a produção de textos por autores nacionais, particularmente pelos docentes atuantes na pós-graduação" (BRASIL, 1986, p. 202).

Apresentada a discussão referente ao III PNPG, evidencia-se os elementos que estiveram em foco, até então, no panorama histórico e legal da pós-graduação. Tais elementos se referem a uma análise dos próprios produtores dos planos, estando presente no IV PNPG, tornando-se assim, substancial para ampliar o olhar para os mesmos.

\begin{abstract}
A partir dessa retrospectiva, pode-se então concluir que a política de pós-graduação no Brasil tentou inicialmente capacitar os docentes das universidades, depois se preocupou com o desempenho do sistema de pós-graduação e, finalmente, voltou-se para o desenvolvimento da pesquisa na universidade, já pensando agora na pesquisa científica e tecnológica e no atendimento das prioridades nacionais. Entretanto, deve-se ressaltar que sempre esteve presente a preocupação com os desequilíbrios regionais e com a flexibilização do modelo de pós-graduação (BRASIL, 2004, p. 15-16).
\end{abstract}

Os referidos planos enfatizam a consolidação do sistema de pós-graduação stricto sensu no cenário nacional. A questão da consolidação foi recorrentemente reiterada, considerando que sua regulamentação aconteceu na década de 1960, o crescimento no que diz respeito ao impacto social em âmbito nacional é expressivo e significativo. Ampliando a discussão, vale salientar que, a partir da análise legal e histórica, um elemento que reforça tal consolidação tem relação com sua constituição organizacional, ou seja, a figura da CAPES. Tal constatação é evidenciada em um dos planos, sendo apontado que:

\begin{abstract}
A CAPES, Fundação articulada ao Ministério da Educação - MEC, tem legalidade, tradição, competência, compromisso e responsabilidade com esse padrão de qualidade. Por isso, enquanto Órgão da União, cabe a ela o papel de coordenar a política do sistema nacional de pós-graduação por meio de sua presença sistemática e qualificada no ensino superior, máxime na pós-graduação, tendo, em relação a todos os programas e aos cursos de pós-graduação stricto sensu, o papel de assegurar a validade nacional dos diplomas. Essa validação, atendendo ao exercício da função normatizadora e avaliadora, garante o funcionamento do sistema nacional como um todo, assegura-lhe a qualidade, evita a duplicação de meios para o mesmo fim, previne a sua fragmentação e promove o mérito (BRASIL, 2004, p. 23).
\end{abstract}

O documento alavanca a CAPES e sua relevância à pós-graduação no país. Pensar em pós-graduação hoje em dia é de forma inerente remeter-se à CAPES e vice-versa. Assim, compreende-se que justamente devido a essa forte regulamentação, advindo de um orgão que desde seus primórdios esteve ligado à instituições de influência no país, é fator que contribuiu para uma sólida configuração atual, bem como, expressiva frente a outros níveis de ensino.

Do terceiro ao quarto plano houve um espaço de tempo em aberto, isto porque os anos de 1990 a 2004 não estão presentes em qualquer Plano Nacional. O IV PNPG se refere aos anos de 2005-2010, e evidencia que redações preliminares foram realizadas, porém, uma série de fatores fizeram que o Plano Nacional em si não se concretizasse anteriormente. 
Uma série de circunstâncias, envolvendo restrições orçamentárias e falta de articulação entre as agências de fomento nacional, impediu que o Documento Final 18 se concretizasse num efetivo Plano Nacional de Pós-Graduação. No entanto, diversas recomendações que subsidiaram as discussões foram implantadas pela Diretoria da CAPES ao longo do período, tais como expansão do sistema, diversificação do modelo de pós-graduação, mudanças no processo de avaliação e inserção internacional da pós-graduação (BRASIL, 2004, p. 17-18).

As palavras mencionadas reforçam o fato de que, mesmo não havendo um documento caracterizado como plano, os elementos presentes nos escritos preliminares foram implantados em outras instâncias legais. Esse dado é relevante, considerando que o período se refere a quatorze anos, bastante tempo no que diz respeito à produção de conhecimento e outros aspectos relacionados à pós-graduação.

Estudando e refletindo os elementos presentes no IV PNPG (2005-2010), chega-se à conclusão de que ele se mostra mais amplo e completo que os planos anteriores. Parece óbvio devido ao fator tempo levantar mais questões a serem retratadas no documento, porém, é relevante enfatizar, visto que, além de discutir questões já preconizadas, ele avança e complexifica as reflexões, ou seja, o fator tempo amadureceu os referidos documentos. Esmiuçando o documento, este se baseia em três itens norteadores que vão se ramificando em especificidades. São eles: 1) situação atual da pós-graduação e diretrizes gerais; 2) cenário de crescimento da pós-graduação; 3 ) metas e orçamento.

Focando especificamente na situação da pós-graduação, o IV PNPG enfatiza o crescimento expressivo de programas em todas as áreas do conhecimento. Em 1976, havia 673 cursos recomendados pela CAPES e, em 2004, o número aumentou para 2.993, com um crescimento de 5,6\% ao ano (BRASIL, 2004). Os números referentes à dependência administrativa do ensino superior revelam a diferenciação entre a universidade pública e privada, tratando-se de educação superior e pós-graduação. Oitenta e dois por cento da oferta dos cursos de mestrado e $90 \%$ dos cursos de doutorado, por exemplo, são de responsabilidade do segmento público, ou seja, os programas presentes em instituições privadas são minorias e com uma quantidade expressivamente menor. No entanto, por sua vez, há uma expansão no setor privado, passando de 87 cursos para 346 no mestrado, e de 44 para 96 no doutorado, no período de 1996 a 2004 (BRASIL, 2004).

Junto ao crescimento apontado, o IV PNPG se reporta às desigualdades regionais, aparente desde a gênese da pós-graduação e recorrentemente abordada como elemento a ser superado. Nesse contexto, a região Sudeste concentra $54,9 \%$ dos cursos de mestrado e $66,6 \%$ dos de doutorado, seguida da região Sul $(19,6 \%$ e $17,1 \%)$, Nordeste $(15,6 \%$ e $10,3 \%)$, Centro-Oeste $(6,4 \%$ e $4,1 \%)$ e Norte (3,5\% e $1,8 \%)$ (BRASIL, 2004, p. 31-32). Houve taxas de crescimento no decorrer dos anos, porém, não o suficiente para superar as expressivas desigualdades históricas entre as regiões. A região Norte foi a que mais se expandiu, seguida da Centro-Oeste, Sul, Nordeste e o Sudeste.

Em relação às bolsas de estudos e à situação da pós-graduação, o documento salienta que não houve redução na concessão entre os períodos de 1991 a 2003, porém, demonstra que a taxa de estudantes matriculados e de forma inerente que possuam bolsa foi diminuindo. Observa-se que esse dado está articulado ao fato de que aumenta-se o número de alunos 
de forma mais expressiva do que o aumento de número de bolsas, então, obviamente, cada vez mais terá estudantes sem o financiamento.

Dando continuidade à situação atual da pós-graduação, o documento apresenta um item interessante, denominado: evolução dos índices de produtividade. Concebe-se como interessante justamente por anunciar diretamente o fator produtividade, elemento amplamente discutido e questionado no meio acadêmico. Nesse momento, ele se baseia em três pontos, como a produção intelectual e a formação de mestres e doutorados em relação aos docentes.

Quanto à produção intelectual, é mencionada uma atividade profícua de publicações, seja em periódicos nacionais, internacionais, eventos entre outros. Assim, os dados apontam que em 1981, enquanto o número de publicações era de 1.901, em 2003, há o crescimento para 12.596 publicações. Esses dados são do Institute for Scientific Information (ISI), ancorados na evolução das citações e do impacto das publicações brasileiras (BRASIL, 2004).

Observa-se, a partir dos dados, que o crescimento em relação às publicações acontece em praticamente todos os anos. Nessa linha histórica de 1981 a 2003, apenas no ano de 1992 para 1993, que se observa um declínio, mesmo que mínimo, variando de 4.591 publicações para 4.427, no entanto, em 1994, a regra de crescimento continua, alcançando o número de 4.811 publicações (BRASIL, 2004).

Em relação à formação, o plano apresenta uma comparação entre o Brasil e outros países. A Alemanha, por exemplo, é o país com maior número de titulação de doutores, atingindo o número de 30 a cada 100 mil habitantes (períodos de 1997-2003), enquanto Estados Unidos e Reino Unido em 2001 atingiram 14 e 24 doutores por 100 mil habitantes. No Brasil, com dados de 2003, foram indicados a formação de 4,6 doutores a cada 100 mil habitantes (BRASIL, 2004). Esses dados revelam que, em um panorama mundial, o Brasil em termos de formação de doutores está bastante aquém dos países que possuem os números mais expressivos. No entanto, tratando-se de publicações em períodicos internacionais, foi constatado que em relação a outros países da América Latina e do mundo, entre os períodos de 1981 a 2003 [...] a produção científica brasileira quintuplicou e sua participação em relação ao resto do mundo triplicou (BRASIL, 2004, p. 40).

Tendo focado principalmente nos direcionamentos e preocupações da pós-graduação contemplados nos documentos, apresenta-se adiante uma breve explanação do contexto social e político em que emergiu cada um dos planos, tomando por base os conhecimentos de Santos e Azevedo (2009), pertinente neste momento da presente pesquisa.

O I PNPG emergiu em um contexto em que havia um projeto de sociedade voltado para o desenvolvimento, daí a ideia de formação humana de alto nível como primordial. Santos e Azevedo (2009, p. 537) reforçam a premissa, mencionando que a pós-graduação exercendo suas funções de forma adequada conseguiria chegar a seu objetivo central "[...] de transformar as universidades em verdadeiros centros de atividades criativas permanentes". Naquele contexto, as ideias que embasavam as políticas e incentivos chegavam à pós-graduação de forma inerente ao contexto militar vivenciado no Brasil.

O contexto é o regime militar e o projeto desenvolvimentista que o acompanhou, ao lado da dura repressão que atingiu as universidades no mesmo período, gerando a situação ambivalente, para não dizer esquizofrênica, em que o professor como classe era reprimido enquanto cidadão e convocado a colaborar com o Estado enquanto acadêmico ou cientista (BARRETO; DOMINGUES, 2012, p. 19). 
O II PNPG foi implementado nos últimos anos do regime militar, e estava envolto em um contexto de crise econômica que se se refletia nas políticas educacionais, fazendo que uma das prioridades estabelecidas para a pós-graduação fosse a racionalização dos investimentos junto ao acompanhamento mais direto dos programas e suas avaliações, focando a qualidade e sua melhoria.

O plano seguinte esteve presente no primeiro governo civil, porém, em um contexto em que o país mantinha heranças de resultados econômicos provenientes da ditadura militar. Dessa forma, nota-se a intenção de uma operacionalização que se contrapõe aos anteriores, com propostas de cunho democratizantes. Assim, o plano buscou o estreitamento entre universidades, a pós-graduação e o setor produtivo.

\begin{abstract}
A recessão dos anos de 1980-1984 veio aprofundar uma crise na universidade que perpassou toda a década de 1980, configurada principalmente pelas limitações de recursos para a pós-graduação. Mas a década também foi caracterizada pela retomada do regime democrático. Nesse contexto, ainda que os recursos tivessem se tornado escassos, observou-se a abertura das decisões e da participação para grupos específicos da sociedade civil, vinculados de algum modo aos estudos pós-graduados e ao setor de ciência e tecnologia (SANTOS; AZEVEDO, 2009, p. 538).
\end{abstract}

Conforme observado, há um espaço de tempo que não consta em qualquer dos PNPG, logo que o terceiro engloba os anos de 1986 a 1989 e o seguinte se reporta aos anos de 2005 a 2010. O interessante nesse momento, é que, segundo os autores supracitados, recorrendo a Ramalho e Madeira (2005), no período que não houve plano oficial aconteceu um salto qualitativo e quantitativo da pós-graduação no Norte e Nordeste, regiões cujos índices estão abaixo da média de outras regiões no cenário nacional. Acerca desse período, Barreto e Domingues $(2012$, p. 20) apontam que mesmo não havendo o plano oficial "[...] porque jamais foi promulgado, mas nem por isso foi menos real e deixou de existir de fato, tendo suas diretrizes adotadas pela CAPES".

Acerca do IV PNPG oficial, datado de 2005 a 2010, primeiramente é necessário observar que engloba mais anos que os demais, sendo uma política de ação para cinco anos. Ele reconhece que a pós-graduação scricto sensu é a etapa da educação mais bem-sucedida no sistema educacional brasileiro, visto que foi fruto de políticas indutivas desenvolvidas com o apoio da sociedade acadêmica (SANTOS; AZEVEDO, 2009). A partir de tal afirmação, concentra-se na ideia de formação qualificada para atuar em diferentes espaços, visando contribuir para a modernização do país. Nota-se que há o retorno de princípios relacionados à pós-graduação e desenvolvimento social, assim como houve em evidência em outros planos nacionais.

No momento de execução da pesquisa encontra-se vigente o V PNPG, que engloba os anos de 2011 a 2020. O Plano apresenta-se em dois volumes, sendo o volume II caracterizado pelos documentos setoriais, ${ }^{9}$ e o volume I o Plano em si, organizado em cinco eixos:

9 Textos elaborados por convidados da Comissão Nacional do PNPG (2011-2020), tendo por objetivo refletir sobre a Pós-Graduação brasileira no contexto de suas respectivas áreas (BRASIL, 2010). 
1) A expansão do Sistema Nacional de Pós-Graduação (SNPG), a primazia da qualidade, a quebra da endogenia e a atenção à redução das assimetrias; 2) A criação de uma nova agenda nacional de pesquisa e sua associação com a pós-graduação; 3) O aperfeiçoamento da avaliação e sua expansão para outros segmentos do sistema de C,T\&I; 4) A multi, e a interdisciplinaridade entre as principais características da pós-graduação e importantes temas de pequisa; 5) $\mathrm{O}$ apoio à educação básica e a outros níveis e modalidades de ensino, especialmente o ensino médio (BRASIL, 2010, p. 15).

De forma inerente à produção do PNPG (2011-2020) estava sendo elaborado o Plano Nacional de Educação (2014-2024) ${ }^{10}$ que, pela primeira vez, “[...] contemplará as propostas de diretrizes e políticas do ensino de pós-graduação, isso porque o PNPG é parte integrante do PNE" (BRASIL, 2010, p. 13). Sem dúvidas, é um marco e um avanço para a pós-graduação estar inserida em uma política que engloba um contexto maior, ou seja, a Educação, independentemente do nível de ensino.

Objetivamente, as indicações e diretrizes presentes em tal planose baseiam nos pontos:

1. a expansão do SNPG; 2. a criação de uma agenda nacional de pesquisa; 3. o aperfeiçoamento da avaliação; 4 . a multi/ criação de uma agenda nacional de pesquisa; 3. o aperfeiçoamento da avaliação; 4. a multi/ interdisciplinaridade; 5. o apoio a outros níveis de ensino (BRASIL, 2010, p. 293).

Pode ser observado que os temas se remetem diretamente à pós-graduação enquanto sistema ao invés de trazer especificidades relacionadas aos programas em si e sua organização. Ao tratar das metas relacionadas à avaliação, um ponto refletido é a questão da indicação de tempo em relação às notas, pois podem influenciar diretamente os programas. Fica recomendado que os programas de notas 6 e 7 possuam um espaço de tempo maior para avaliação do que os programas avaliados em 3, 4 e 5. Há a preocupação do aferimento de forma mais constante aos programas de menor nota, dessa forma, pode ser inferido que os prazos mais alargados destinados aos programas de maior nota representam um menor controle a estes por estarem inseridos no padrão imposto, enquanto que os em crescimento (de nota) necessitam ser averiguados de maneira mais intensa.

Ainda no quesito avaliação, nota-se que há diretrizes que permitem flexibilidade em relação às diferentes áreas. Alguns itens avaliativos podem ser contemplados em determinadas áreas e em outras não, então, no plano fica evidenciado que "[...] a avaliação dos programas deverá incorporar crescentemente parâmetros além daqueles tradicionalmente adotados nas áreas básicas e acadêmicas" (BRASIL, 2010 p. 295). Como os programas não possuem autonomia nos quesitos que serão avaliados, entende-se que a afirmação supracitada diz respeito às especificidades das áreas, elemento a ser considerado, justamente devido às particularidades.

Além de tais pontos, merece destaque a abordagem a uma questão fortemente discutida nos documentos desde a gênese da pós-graduação stricto sensu, que é a redução das disparidades regionais. É mencionado que os indicadores poderão utilizar-se de elementos

$10 \quad$ Lei n. $13.005 / 2014$. 
que contemplem a redução das assimetrias, porém, também fica enfatizado que será possível caso sejam assegurados os critérios de excelência. Na íntegra: “[...] a avaliação dos programas, assegurados os critérios de excelência poderá utilizar indicadores que contemplem a redução das assimetrias acadêmicas" (BRASIL, 2010, p. 295).

É necessário refletir tal ponto justamente pela sua contradição aparente. Se há as assimetrias, é porque alguns programas não conseguem atingir os critérios impostos, dessa forma, inserir elementos que podem diminuir as assimetrias seria refletir para além dos já impostos. No entanto, ao mencionar a necessidade de garantir os critérios de excelência, fica entendido que os critérios se manterão, então, os programas com menores notas deverão atingí-los caso queiram se sobressair, e somente haverá critérios diferenciados a partir dos que já estão vigentes.

Complicado pensar que não há a possibilidade de redução das assimetrias, a partir de critérios diferenciados dos já estabelecidos. Mais complicado aindaé compreender a falta de flexibilidade acerca dessa questão, principalmente considerando que já foi comprovado historicamente que as assimetrias estão presentes e que não será simples diminuí-las de forma substancial. Esse critério explica de forma direta as diferentes ações relacionadas às regiões com programas com menor nota, pois, a partir daí entende-se por que há medidas para além dos critérios avaliativos. Justamente pois estes deverão manter-se intactos, podendo ser pensados prolongamentos, mas não alterá-los, sendo considerados de excelência.

As assimetrias correspondem a itens específicos em tais diretrizes, sendo anunciadamente direcionados a diferentes orgãos do Governo Federal e parcerias das Fundações de Amparo à Pesquisa nos Estados. Dizem respeito à indução de programas, formação regional de recursos humanos, bem como, à adoção de mecanismos que possam corrigir as distorções nas regiões, nas áreas do conhecimento e no sistema de ensino. O último item resume de forma substancial as ideias que permeiam as reflexões trazidas acerca das assimetrias, no entanto, não chegam a apontar medidas específicas, exceto as já mencionadas que, de modo alinhado à discussão anterior, não interferem nos itens já constituídos em avaliação, apenas prolongam as ações.

Destaca-se que o plano vigente considera as assimetrias de forma diferenciada dos demais, conforme explicação:

\footnotetext{
Nos Planos anteriores, a questão das assimetrias foi focalizada tomando-se como parâmetro as regiões e as unidades da federação. No Plano 2011-2020 será adotada a distribuição geográfica por mesorregião. A incorporação desse indicador agrega precisão ao diagnóstico. Com isso torna-se possível identificar diferentes graus de consolidação na formação de recursos humanos em nível de pós-graduação, desde a incipiência até excelência, independentemente da unidade da federação ou macrorregião (BRASIL, 2010, p. 297).
}

Por se tratar de um tema recorrentemente evidenciado, seja na produção literária da área, seja nos documentos afins, nota-se, a partir de tal alteração, por exemplo, que as medidas de análise, bem como, de elementos que permitem criação de novas medidas, estão sendo modificados, indicando a predisposição do Sistema Nacional de Pós-Graduação ao combate assimétrico e disparidade no cenário nacional.

As diretrizes relacionadas aà questões interdisciplinares também estão em evidência 
no plano discutido. Isto porque parte-se do pressuposto de que "[...] a busca da excelência e do conhecimento novo passa hoje fortemente pelas abordagens e práticas multi e interdisciplinares" (BRASIL, 2010, p. 296). Para tal, fica direcionado que os programas tenham suas disciplinas, áreas de concentração, linhas de pesquisas, entre outros elementos, articuladas, de modo "[...] que promovam a convergência de temas e o compartilhamento de problemas, em vez da mera agregação ou justaposição" (BRASIL, 2010, p. 296).

Considerando a mencionada criação, na CAPES, da Diretoria de Educação Básica Presencial e da Diretoria de Educação a Distância, algumas diretrizes recaem na articulação entre a pós-graduação e a educação básica, bem como, nestas com o vigente Plano Nacional de Educação (2014-2024). Assim, há de forma direta o incentivo à ampliação de programas que valorizem a formação dos profissionais do magistério da educação básica, bem como, a articulação entre a Pós-Graduação e os cursos de licenciatura.

Nesse quesito, há um item que merece destaque, visto seu direcionamento ao "[...] estímulo ao desenvolvimento de estudos visando à formatação do ensino de ciências na educação básica, instrumento fundamental para a construção da cidadania" (BRASIL, 2010, p. 299). O referido item encerra-se por aqui, no entanto, a utilização da nomenclatura formatação e a colocação acerca do ensino de ciências de forma articulada à construção da cidania geraram algumas dúvidas sobre a assertiva. Não há ligação direta à pesquisa $\mathrm{e}$ seu objetivo, porém, gerou reflexão e desconforto visto a rigidez da diretriz, bem como, da elevada responsabilidade ao ensino de ciências como fundamental para a construção da cidadania, um dos fatores constituintes do ser humano múltiplo que somos.

A indução de medidas de recursos humanos para empresas também foi evidenciada, considerando o fato de que a formação na pós-graduação stricto sensu demonstrou por intermédio de dados e do próprio plano, que também garantiu grande parte de profissionais fora do âmbito acadêmico. Assim, há direcionamentos relacionados à articulação universidade e empresa, evidenciando, entre outros elementos, o estímulo à formação para inovações tecnológicas e empreendedorismo, para além de atividades de pesquisa.

A internacionalização é evidenciada nas diretrizes, ficando apontado que sejam enviados maiores números de estudantes de doutorado para a realização de seu estudo no exterior, dinamizando o sistema e visando a apropriação de novos conhecimentos, bem como, a inserção de estudantes estrangeiros no cenário brasileiro e a produção de pesquisas em âmbito internacional. Tais quesitos estão presentes nas discussões dentro dos programas, considerando os critérios avaliativos, bem como, a necessidade de tais pressupostos para que sejam atingidos os conceitos superiores da CAPES, como o 6 e 7.

\section{CONSIDERAÇÕES FINAIS}

Visando compreender o processo da pós-graduação stricto-sensu no Brasil, o presente estudo pautou-se nos documentos legais que foram substanciais para a consolidação desse nível de ensino no cenário nacional. Tais documentos expressam as necessidades, projeções e intenções de sua época, no entanto, não se esgotam necessariamente na temporalidade que englobam. 
O Parecer n. 977, de 3 de dezembro de 1965, intitulado "Definição dos cursos de pós-graduação" é apontado, seja em documentos posteriores, seja na literatura da área, como precursor legal, bem como, impulsionador da pós-graduação. Além de que estabeleceu diretrizes que perpetuam até os dias atuais, tornando-se um clássico, e mais que isso, representa um documento base, conhecimento necessário aos interessados no estudo e na compreensão da pós-graduação stricto sensu no país.

Para além de tal política, o Plano Nacional de Pós-Graduação (PNPG) torna-se o pano de fundo para direcionamentos relacionados a esse nível de ensino, iniciando na década de 1970 e perpetuando até os dias atuais, estando em vigência o quinto plano oficial. O supracitado documento contextualiza a pós-graduação, no período em que aborda, garantindo a compreensão histórica do desenvolvimento e das diferentes abordagens e direcionamentos relacionados a cada época.

Dessa forma, a partir de tais documentos, pode ser observado que há uma linearidade histórica e social bem expressivas, ou seja, se inicia com a necessidade de implementação legal da pós-graduação no país, frente a um contexto de abertura de cursos de forma desalinhada. Assim, os documentos se pautam em modelos já estabelecidos, preconizando conceitos e formas de organização que podem ser observados também nos documentos atuais.

Valorizada e incentivada a expansão da pós-graduação stricto sensu, o aferimento da qualidade dos referidos cursos passa a ser objeto de preocupação. Ficando em um primeiro momento o controle e a manutenção a cargo das próprias universidades, não é possível mensurar a formação concebida, assim, o controle de qualidade passa a se tornar objeto central, sendo concebida a avaliação da pós-graduação, que ainda que não tenha sido objeto central de discussão neste artigo, esteve presente de modo mais tímido e, posteriormente, mais enfatizado, a partir do II PNPG.

A necessidade de mensurar a formação, bem como, quantificar e qualificar a produção existente nos programas, seja pelos docentes ou discentes, são elementos que vão ganhando forma e força no decorrer dos anos, chegando a um ponto, de no plano vigente, passar a ser questionada a avaliação atual e seus pressupostos, visto que há o fato da disparidade regional no cenário nacional, no que diz respeito às notas dos programas em relação às diferentes regiões do país, bem como, à própria quantidade de programas concentrados, principalmente, nas regiões Sul e Sudeste.

Aliás, o fator disparidade se mostra como um dos, senão o principal, desafios ao sistema de pós-graduação, visto que acontece desde os primórdios, como pode ser analisado nos planos. A pós-graduação stricto sensu se apresenta hoje com um sistema consolidado de ensino no país, estando cada vez mais articulado a outras instâncias e níveis de ensino. Torna-se, dessa forma, um sistema cada vez mais complexo, outro elemento identificado no estudo dos referidos documentos.

Ao modo que vai se constituindo no decorrer dos anos, as necessidades, bem como reflexões acerca do mesmo vão permitindo tal complexificação, o que pode ser considerado relevante, visto que a manutenção e possíveis melhoras partem justamente de uma vigilância crítica sobre o estabelecido.

O presente tema torna-se relevante, para além dos elementos supracitados, para trazer à tona o nível de ensino que hoje é referência no país, porém, não possui número expres- 
sivo de pesquisas, assim como acontece com a educação básica e suas especificidades, por exemplo. Falar da pós-graduação stricto sensu, discutir e refletir sobre seus aspectos, é valorizar e fomentar estudos que contribuem diretamente para a promoção de pesquisas no país, logo que, é nesse nível de ensino que há o avanço do conhecimento, seja por meio das teses e dissertações, ou, das produções necessárias para que os programas de pós-graduação se mantenham.

\section{REFERÊNCIAS}

BARRETO, Francisco César de Sá; DOMINGUES, Ivan. O PNPG 2011-2020: os desafios do país e o sistema nacional de pós-graduação. Educação em Revista. Belo Horizonte, v. 28, n. 03, p. 17-53. set. 2012.

BRASIL. Conselho de Ensino Superior. Parecer no ${ }^{\mathbf{0}}$ 977/65, aprovado em: 3 dez. 1965.

BRASIL. Ministério da Educação e Cultura, Secretaria de Educação Superior/Coordenação de Aperfeiçoamento de Pessoal de Nível Superior, (1975). I Plano Nacional de Pós-Graduação: 1975-1979. Brasília: MEC/SESU/CAPES, 1975.

BRASIL. Coordenação de Aperfeiçoamento de Pessoal de Nível Superior-CAPES. Plano Nacional de Pós-graduação [PNPG] 2011-2020. Brasília: CAPES, 2010, v. 1.

BRASIL. Coordenação de Aperfeiçoamento de Pessoal de Nível Superior-CAPES. Plano Nacional de Pós-graduação [PNPG] 1982-1985. Brasília: CAPES, 1982, v. 1.

BRASIL. Coordenação de Aperfeiçoamento de Pessoal de Nível Superior-CAPES. Plano Nacional de Pós-graduação [PNPG] 1986-1989. Brasília: CAPES, 1986, v. 1.

BRASIL. Coordenação de Aperfeiçoamento de Pessoal de Nível Superior-CAPES. Plano Nacional de Pós-graduação [PNPG] 2005-2010. Brasília: CAPES, 2004, v. 1.

CURY, Carlos Roberto Jamil. Quadragésimo ano do parecer CFE no 977/65. Revista Brasileira de Educação, set./out./nov./dez. 2005, n. 30, p. 7-20.

HOSTINS, Regina Célia Linhares. Os Planos Nacionais de Pós-graduação (PNPG) e suas repercussões na Pós-graduação brasileira. Perspectiva, Florianópolis, v. 24, n. 1, p. 133160, jan./jun. 2006.

RAMALHO, Betania Leite; MADEIRA, Vicente de Paulo C. A pós-graduação em educação no Norte e Nordeste: desafios, avanços e perspectivas. Revista Brasileira de Educação, n. 30, p. 70-81, n. esp., set./dez. 2005. 
SANTOS, Ana Lúcia Felix dos; AZEVEDO, Janete Maria Lins de. A pós-graduação no Brasil, a pesquisa em educação e os estudos sobre política educacional: os contornos da constituição de um campo acadêmico. Revista Brasileira de Educação, v. 4, n. 42, set./ dez. 2009.

SUCUPIRA, Newton, (1980). Antecedentes e primórdios da pós-graduação. Fórum Educacional. Rio de Janeiro: Fundação Getúlio Vargas, ano 4, no . 4, out./dez. p. 3-18, 1980.

\section{DADOS DOS AUTORES:}

\section{Nathália Delgado Bueno da Silva}

Doutoranda e mestre em Educação pela Universidade Estadual Paulista Júlio de Mesquita Filho. Marília/SP-Brasil.nathdelgado89@hotmail.com

\section{Carlos da Fonseca Brandão}

Pós-doutor pela Universidad Autónoma de Barcelona, pela Universitat Rovira I Virgili e pela Uppsala Universitet .Professor do Programa de Pós-graduação em Educação da Universidade Estadual Paulista Júlio de Mesquita Filho. Marília/SP-Brasil e Livre-docente em Estrutura e na Universidade Estadual Paulista Júlio de Mesquita Filho, Assis/SP-Brasil. cd.brandao@uol.com.br

Submetido em: 30-5-2019

Aceito em: 30-6-2020 